\title{
A cohort study of the association between secondary sex ratio and parental exposure to polybrominated biphenyl (PBB) and polychlorinated biphenyl (PCB)
}

\author{
Metrecia L Terrell*1, Alissa K Berzen ${ }^{1}$, Chanley M Small ${ }^{1}$, \\ Lorraine L Cameron ${ }^{2}$, Julie J Wirth ${ }^{2,3,4}$ and Michele Marcus ${ }^{1,5}$
}

Address: ${ }^{1}$ Department of Epidemiology, Rollins School of Public Health, Emory University, 1518 Clifton Rd, Atlanta, Georgia, 30322; USA, ${ }^{2}$ Division of Environmental Health, Michigan Department of Community Health, 201 Townsend, Lansing, Michigan, 48913; USA, ${ }^{3}$ Department of Epidemiology, Michigan State University, East Lansing, Michigan, 48824; USA, ${ }^{4}$ Departments of Obstetrics and Gynecology, Michigan State University, East Lansing, Michigan, 48824; USA and ${ }^{5}$ Department of Environmental and Occupational Health, Rollins School of Public Health, Emory University, Atlanta, Georgia, 30322, USA

Email: Metrecia L Terrell* - mterrel@emory.edu; Alissa K Berzen - akberzen@dhr.state.ga.us; Chanley M Small - csmall@emory.edu; Lorraine L Cameron - cameronl@michigan.gov; Julie J Wirth - wirthjul@michigan.gov; Michele Marcus - mmarcus@emory.edu

* Corresponding author

Published: 15 August 2009

Environmental Health 2009, 8:35 doi:10.1 186/1476-069X-8-35
Received: 17 February 2009

Accepted: 15 August 2009

This article is available from: http://www.ehjournal.net/content/8/I/35

(c) 2009 Terrell et al; licensee BioMed Central Ltd.

This is an Open Access article distributed under the terms of the Creative Commons Attribution License (http://creativecommons.org/licenses/by/2.0), which permits unrestricted use, distribution, and reproduction in any medium, provided the original work is properly cited.

\begin{abstract}
Background: Polybrominated biphenyl (PBB), a brominated flame retardant, was accidently mixed into animal feed in Michigan (1973-1974) resulting in human exposure through consumption of contaminated meat, milk and eggs. Beginning in 1976 individuals who consumed contaminated products were enrolled in the Michigan Long-Term PBB Study. This cohort presents a unique opportunity to study the association between parental exposures to PBB and offspring sex ratio.

Methods: We identified offspring of female PBB cohort participants (born 1975-1988) and obtained electronic birth records for those born in the state of Michigan. We linked this information to parental serum PBB and PCB concentrations collected at enrollment into the cohort. We modeled the odds of a male birth with generalized estimating equations accounting for the nonindependence of siblings born to the same parents. We explored potential confounders: parental age and education at offspring's birth, parental body mass index at cohort enrollment, birth order, gestational age and year of offspring's birth.
\end{abstract}

Results: The overall proportion of male offspring among 865 live births to cohort mothers was 0.542 . This was higher than the national male proportion of 0.514 (binomial test: $p=0.10)$. When both parents were in the cohort $(n=300)$, we found increased odds of a male birth with combined parents' enrollment PBB exposure $\geq$ the median concentrations $(3 \mu \mathrm{g} / \mathrm{L}$ for mothers; $6 \mu \mathrm{g} /$ $L$ for fathers) compared to combined parents' PBB exposure < the median concentrations ( $A O R=1.43,95 \%$ Cl: 0.89-2.29), although this did not reach statistical significance. In addition, there was a suggestion of increased odds of a male birth for combined parents' enrollment PCB exposure $\geq$ the median concentrations $(6 \mu \mathrm{g} / \mathrm{L}$ for mothers; $8 \mu \mathrm{g} / \mathrm{L}$ for fathers $)$ compared to combined parents' enrollment PCB exposure $<$ the median concentrations ( $\mathrm{AOR}=1.53,95 \% \mathrm{Cl}: 0.93-2.52)$.

Conclusion: This study adds to the body of literature on secondary sex ratio and exposure to environmental contaminants. In this population, combined parental exposure to PBBs or PCBs increased the odds of a male birth. Further research is needed to corroborate these findings and shed light on the biological mechanisms by which these types of chemicals may influence the secondary sex ratio. 


\section{Background}

Polybrominated biphenyl (PBB), a brominated flame retardant, was used in the United States in the 1970's and added to commercial products such as plastics, textiles, and electronics. The manufacture of PBB was discontinued in the United States in 1976 following a large-scale contamination incident. In 1973, a company that manufactured two products (FireMaster, a fire retardant mixture of PBBs and NutriMaster, a feed-grade magnesium oxide supplement for cattle) inadvertently delivered FireMaster to Michigan Farm Bureau Services where it was mixed into animal feed that was shipped to feed mills across the state. Between 1973 and 1974, the PBB-contaminated feed was ingested by animals, and ultimately by Michigan residents through meat, milk, eggs and other animal products. Most Michigan residents had low but detectable concentrations of PBB in their serum; however, high PBB concentrations were detected in families residing on quarantined farms which received the contaminated feed and in neighboring families who purchased food from these farms. Nearly 4,000 of these individuals were enrolled in a cohort study established in 1976 by the Michigan Department of Public (now Community) Health to track the long-term health effects of PBB exposure [1]. This cohort has been followed prospectively since that time, and by design includes information linking family members. Details of the incident and earlier studies have been described elsewhere [2-4]. Additionally, a number of studies have been conducted in this cohort investigating associations between PBB and PCB exposure and reproductive health outcomes [5-10].

PBBs belong to a class of structurally similar chemicals known as polyhalogenated aromatic hydrocarbons, which includes other potential endocrine disruptors such as dioxins, furans, and polychlorinated biphenyls (PCBs). PCBs were manufactured in the United States from the 1930 's to 1970 's and used as lubricants and coolants in electrical equipment [11]. Evidence of the toxic effects of PCBs and their accumulation in the environment led to their ban in the late 1970's. Because there was concern for widespread human PCB exposure, Michigan PBB cohort members also had PCB exposure concentrations measured at enrollment into the PBB cohort; PCB concentrations were similar to that in the general population $[12,13]$. The primary source of exposure to PCB in the general population is through contaminated food; mostly from fish obtained from PCB-contaminated waters [11]. Although the production of PBBs and PCBs has ceased, they remain a public health concern because of their environmental persistence. The estimated half-life of PBB in humans is about 10.8 years [14], and ranges from 13-29 years in females [15]. The estimated half-life of PCBs in humans ranges from less than one to 10 years or more (reviewed in [16]). In addition, PBBs and PCBs are lipophilic and can be transferred in utero and through breast milk [17-19].

The secondary sex ratio, defined as the ratio of males to females at birth, is of interest in the scientific community. Studies have suggested that this ratio is declining in the United States and in other countries [20-23]. Generally held to be about 104 to 106 males to 100 females worldwide, a number of factors are suspected to influence the sex ratio, including maternal and paternal age, birth order, plurality, and race/ethnicity (reviewed in $[21,24,25]$ ). In addition, there is increasing evidence that exposure to environmental toxins, including endocrine disruptors may influence the sex ratio. While some epidemiological studies have reported decreases in the secondary sex ratio as a result of parental exposures, others have not. The 1976 Seveso, Italy industrial accident in which some residents were exposed to high levels of dioxins, found a significant decline in males births in couples in which the fathers were highly exposed [26]. Studies in other populations, have also reported a reduced sex ratio with parental exposure to dioxins, PCBs and related environmental pollutants [27-32]. However, some studies have suggested increases or little if any association between exposure to environmental pollutants and the secondary sex ratio [31,33-36]. The Michigan Long-Term PBB Study presents a unique opportunity to study the association of parental exposures to $\mathrm{PBB}$ and $\mathrm{PCB}$ and the sex ratio at birth of their offspring.

\section{Methods \\ Study Population}

The participants of the present study were the offspring of female PBB cohort members born during 1975-1988, potentially exposed to maternal PBB in utero. Birth records were available beginning in 1975 and birth records after 1988 were excluded because after this time there were no births in which the father was a cohort member. Earlier births (those closer to the contamination period) were more likely from parents who were both enrolled in the cohort. Most cohort members were enrolled as part of a household that lived or purchased food from a quarantined farm.

Offspring were identified by matching demographic information of cohort mothers (born before July 1973) to maternal information in the Michigan electronic birth files. These matches were verified using cohort registry records, and additional births were identified from cohort infant enrollment records. We could not obtain electronic birth records for offspring born outside Michigan so these births were excluded $(\mathrm{n}=84)$. Paternal information, father's name and age were determined from a manual search of cohort registry records and checked against paper copies of the birth certificate. The studies from 
which these data were derived have undergone human subjects review and approval by IRBs at the Michigan Department of Community Health and Emory University and informed consent was obtained from all participants.

\section{Exposure assessment}

The Michigan PBB cohort was predominately exposed to a mixture of PBBs that contained mostly PBB-153 (60\%) [37]. PBB-153, or 2,2'4,4'5,5'-hexabromobiphenyl, was measured in serum samples collected from PBB cohort participants by the Michigan Department of Community Health Bureau of Laboratories. The serum samples were first extracted with 1:1 petroleum ether-ethyl or 1:1 hexane-ether, and then passed through either a Florisil or Florisil and silica gel column. PBBs were detected and quantitated using gas chromatography with electron capture detection. The coefficients of variation ranged from $7.1 \%$ to $14.0 \%[38,39]$ and the limit of detection (LOD) was one microgram per liter $(\mu \mathrm{g} / \mathrm{L})$. PCB determination was based on Aroclor 1254. The coefficients of variation ranged from $12 \%$ to $30 \%[38,39]$ and the LOD was $5 \mu \mathrm{g} /$ L. The Bureau of Laboratories used a Double Determination method which measured both total PBB and total PCB exposure in the same serum sample, so both concentrations were available for $85 \%$ of cohort members. All serum samples were collected from non-fasting participants, and lipids were not measured.

Serum samples from most of the parents were collected in 1976-1979 when they enrolled in the PBB cohort. Maternal samples were collected on average four years after their offspring's birth (range: three years before to 12 years after offspring's birth) and paternal samples were collected on average one year after their offspring's birth (range: three years before to 11 years after offspring's birth). Because of these varying times from the parents' blood collection to the offspring's birth, we estimated maternal and paternal $\mathrm{PBB}$ at the time of conception of the offspring based on a one-compartment first-order mixed-effects decay model [40]. For the estimated maternal PBB, we calculated a decay estimate $(\lambda)$ using the parameters specified in the decay model described in Terrell et al. [40], which includes the mother's age at exposure to PBB, body mass index (BMI), smoking history, parity, and breast-feeding history. We then calculated the estimated PBB based on the formula [estimated PBB = enrollment PBB $\times \exp (\lambda t)]$, where $(\mathrm{t})$ is the time between the offspring's conception date and the date when the mother's serum sample was collected. Likewise, we developed a decay model for paternal PBB exposure using a similar methodology as described in Terrell et al. [40]. The estimated paternal PBB was calculated using the above formula. The decay estimate $(\lambda)$ was based on the father's age at exposure to PBB and $B M I$ and $(t)$ was the time between the offspring's conception date and the date when the father's serum sample was collected. Because some parents in the present study did not have their enrollment PBB concentration measured before the birth of their offspring, the decay model extrapolated backwards for those offspring born before their parent's PBB concentrations were measured. Because this cohort had relatively low serum PCB concentrations, we used the parents' PCB level collected at the PBB study enrollment period as the estimate of PCB exposure at the time of the offspring's conception.

\section{Statistical data analysis}

Information from the electronic birth file used in this study included: offspring's sex, mother's age at offspring's birth (as a continuous variable and in categories split at the $90^{\text {th }}$ percentile of $<30$ and $\geq 30$ years), father's age at offspring's birth (as a continuous variable and in categories split at the $90^{\text {th }}$ percentile of $<35$ and $\geq 35$ years), mother's education at offspring's birth ( $\leq \mathrm{HS}$ and $>\mathrm{HS}$ ), father's education at offspring's birth ( $\leq \mathrm{HS}$ and $>\mathrm{HS}$ ), birth order (first-born and non first-born), plurality (for exclusion of multiple births), gestational age (for calculation of conception date and as a covariate), and father's race (for exclusion of non-white fathers). The population of the Long-Term study was $98 \%$ white, so we excluded offspring if the father's race was listed as non-white or missing on the birth record.

Parental information obtained from historic records of the Long-Term PBB Study included: earliest (enrollment) serum PBB and PCB exposure measurements and height and weight at enrollment to calculate body mass index (BMI). Analyses that included BMI were restricted to females at least 16 years old at enrollment in the cohort and males at least 19 years old at enrollment in the cohort, accounting for later growth spurts that often occur in males. BMI was categorized based on standard classifications from CDC of under $\left(<18.5 \mathrm{~kg} / \mathrm{m}^{2}\right)$, normal $(18.5-$ $\left.24.9 \mathrm{~kg} / \mathrm{m}^{2}\right)$ and overweight $\left(\geq 25 \mathrm{~kg} / \mathrm{m}^{2}\right)$ and also as a two-level variable for overweight versus normal and underweight combined.

Additional maternal information was obtained from structured telephone interviews conducted with female cohort members during 1997-1998 and 2003-2006 which collected detailed reproductive, hormonal, and lifestyle information. From the telephone interviews we obtained data on months of unprotected intercourse to achieve the pregnancy ( $1-3$ months and $>3$ months) and when not available in the electronic birth file, information on offspring's gestational age and birth order.

For the exposure variables, $\mathrm{PBB}$ and $\mathrm{PCB}$ concentrations were modeled as: two groups, split at the median concentrations (medians: $3 \mu \mathrm{g} / \mathrm{L}$ for maternal enrollment PBB, 2 $\mu \mathrm{g} / \mathrm{L}$ for maternal estimated PBB, $6 \mu \mathrm{g} / \mathrm{L}$ for paternal enrollment and estimated PBB, $6 \mu \mathrm{g} / \mathrm{L}$ for maternal PCB, and $8 \mu \mathrm{g} / \mathrm{L}$ for paternal PCB); and as continuous variables, 
log-transformed because of their skewed distributions. In order to evaluate a possible dose response, we also categorized enrollment PBB and estimated PBB concentrations into three groups based on the limit of detection and the median concentration of those above. The categories were (low: $\leq 1$, moderate: $>1-<4$, high: $\geq 4 \mu \mathrm{g} / \mathrm{L}$ ) for maternal PBB and (low: $\leq 1$, moderate: $>1-<6$, high: $\geq 6 \mu \mathrm{g} / \mathrm{L}$ ) for paternal PBB.

We were interested in modeling the probability of a male birth in relation to parents' PBB or PCB exposure concentrations. We used logistic regression analyses to model the odds of a male birth and calculated unadjusted odds ratios, adjusted odds ratios (AOR) and 95\% confidence intervals (CI). Because the Long-Term study was, by design a cohort of families, our study population of offspring included up to five siblings. Therefore, all analyses were performed using generalized estimating equations (GEE) to account for the lack of independence between offspring from the same family (link = logit; covariance structure $=$ exchangeable). . To assess potential confounding, we explored the unadjusted associations between each covariate and the outcome, and each covariate with the exposure variables (cut-off $\mathrm{p}<0.10$ ). In multivariate analyses, we ran a series of models with potential confounders and maternal or paternal enrollment $\mathrm{PBB}$, estimated PBB at conception or enrollment PCB exposure. Year of offspring's birth was included as a covariate in all adjusted models. Covariates were removed sequentially using backward elimination and were retained if the main exposure odds ratios changed by at least ten percent. We examined models where maternal and paternal exposure were modeled separately and combined. However, because maternal and paternal serum concentrations were correlated, we did not include them in a model simultaneously. Finally, to examine combined parents' exposure (interaction term), we considered only three categories: where both parents had exposure $<$ the median concentrations (referent group), where both parents had exposure $\geq$ the median concentrations, and the combination of parents' with discordant exposure levels. All analyses were performed using SAS v9.2 [41].

\section{Results \\ Population characteristics}

In total, we identified 922 Michigan born offspring to 496 PBB cohort mothers from linkage with electronic birth records. For 366 of these offspring, we identified 208 fathers who were also participants in the PBB cohort. We excluded offspring from the study for the following reasons: no maternal PBB measurement $(\mathrm{n}=33)$; father's race missing or listed as non-white on the offspring's birth record $(\mathrm{n}=8)$; and non-singleton births $(\mathrm{n}=16)$. Thus, our final sample included 865 Michigan born offspring to 479 PBB cohort mothers. Of these, 300 offspring had mothers and fathers who were both in the cohort ( $\mathrm{n}=171$ pairs of mothers and fathers). The overall proportion male among the 865 offspring was 0.542 (corresponding sex ratio $=1.18$ ). The proportion male among these offspring was slightly higher than the national male proportion [21] of 0.514 (binomial test: $\mathrm{p}=0.10$ ).

\section{$P B B$ and $P C B$ concentrations}

The mean age of mothers during the PBB exposure period (based on age in 1973) was 17 years (range: infancy-38 years). Fathers' mean age during the PBB exposure period was 25 years (range: 13-61 years). In general, fathers had higher $\mathrm{PBB}$ and $\mathrm{PCB}$ concentrations than the mothers (maternal PBB range: < LOD-933 $\mu \mathrm{g} / \mathrm{L} ; 20 \%<$ LOD; paternal PBB range: < LOD-1744 $\mu \mathrm{g} / \mathrm{L} ; 5 \%<\mathrm{LOD}$; maternal PCB range: < LOD-78 $\mu \mathrm{g} / \mathrm{L} ; 43 \%<\mathrm{LOD}$; paternal PCB range: < LOD-85 $\mu \mathrm{g} / \mathrm{L} ; 17 \%<\mathrm{LOD})$. There were positive, although weak correlations between mothers' log-transformed PBB and PCB concentrations $\left(\mathrm{n}=434\right.$ mothers, $r_{\mathrm{s}}$ $=0.14, \mathrm{p}=0.004)$ and between fathers' log-transformed PBB and PCB concentrations $\left(n=162\right.$ fathers, $r_{s}=0.13, p$ $=0.10)$. As shown in Figure 1, serum PBB concentrations were much higher than serum PCB concentrations. In addition, there was a significant positive relationship between mothers' and fathers' log-transformed exposure concentrations for PBB $\left(r_{s}=0.64, p<0.001\right)$ and PCB $\left(r_{s}\right.$ $=0.19, \mathrm{p}=0.002$ ).

\section{Association with sex ratio}

Table 1 gives results from unadjusted GEE models examining the odds of a male birth among offspring whose mothers' were in the cohort by potential confounding variables ( $\mathrm{n}=865$ offspring, $\mathrm{n}=479$ mothers). Although the results for paternal BMI and offspring gestational age were imprecise, increased odds of a male birth were seen for offspring born to fathers with high paternal BMI at enrollment (BMI $\geq 25 \mathrm{~kg} / \mathrm{m}^{2}$ ) compared to fathers with normal paternal BMI at enrollment $\left(18.5-24.9 \mathrm{~kg} / \mathrm{m}^{2}\right)(\mathrm{OR}=$ 1.43, 95\% CI: 0.98-2.09) and for offspring born before 37 weeks gestation than offspring born 37 to $<42$ weeks gestation $(\mathrm{OR}=1.78,95 \% \mathrm{CI}: 0.86-3.67)$. The other covariates, maternal or paternal age during the PBB exposure period, maternal or paternal age at offspring's birth, maternal BMI at enrollment, maternal or paternal education at offspring's birth, months of unprotected intercourse to achieve the pregnancy and birth order showed little association with the odds of a male birth.

We present the crude (unadjusted for offspring born to the same mother or father), unadjusted and adjusted GEE models for the odds of a male birth by parents' enrollment PBB exposure in Table 2.

In the model with only maternal PBB exposure (Model 1), there was little effect of exposure on the odds of a male 


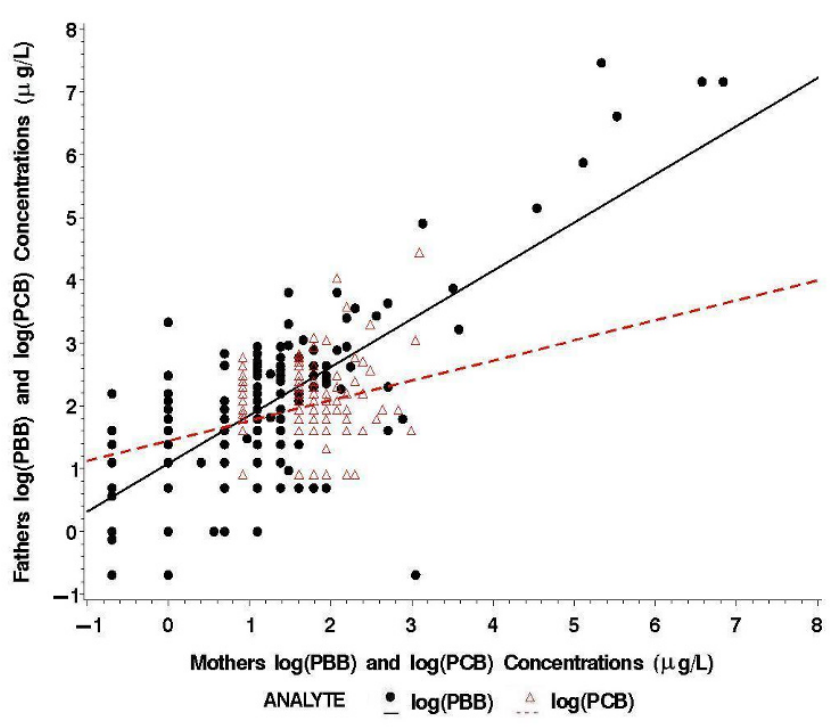

Figure I

Relationship between parents' serum log-transformed PBB and log-transformed PCB concentrations ( $\mathbf{N}=\mathbf{3 0 0}$ offspring). Spearman correlation coefficients: $P B B, r_{s}=0.64 ; P C B, r_{s}=0.19$.

birth for offspring born to mothers with $\mathrm{PBB} \geq 3 \mu \mathrm{g} / \mathrm{L}$ compared to mothers with $\mathrm{PBB}<3 \mu \mathrm{g} / \mathrm{L}$ ( $\mathrm{n}=865$ offspring, $\mathrm{n}=479$ mothers; $\mathrm{AOR}=0.93,95 \% \mathrm{CI}: 0.72,1.20)$. There was a small increase in the odds of a male birth in the model with only paternal PBB exposure (Model 2, $\mathrm{n}=$ 300 offspring, $\mathrm{n}=171$ fathers) with an adjusted odds ratio of 1.18 (95\% CI: $0.76,1.83)$ for offspring born to fathers with $\mathrm{PBB} \geq 6 \mu \mathrm{g} / \mathrm{L}$ compared to fathers with $\mathrm{PBB}<6 \mu \mathrm{g} / \mathrm{L}$. When we considered the model with combined maternal and paternal PBB exposure, the odds ratio for offspring where both parents had PBB exposure $\geq$ the median concentrations ( $\geq 3 \mu \mathrm{g} / \mathrm{L}$ for mothers and $\geq 6 \mu \mathrm{g} / \mathrm{L}$ for fathers) compared to where both parents had PBB exposure $<$ the median concentrations was increased, but imprecise (Model 3, $\mathrm{n}=300$ offspring, $\mathrm{n}=171$ pairs of mothers and fathers). The adjusted odds ratio was 1.43 (95\% CI: 0.89, 2.29), when adjusted for paternal BMI and year of offspring's birth.

Table 3 shows the results when we modeled the odds of a male birth by estimated PBB at the conception date of the offspring. The odds ratios in models $1-3$ with estimated PBB were similar to those with enrollment PBB in Table 2. In model 3 ( $\mathrm{n}=226$ offspring, 131 pairs of mothers and fathers), the adjusted odds ratio of a male birth for parents with estimated $\mathrm{PBB}$ exposure $\geq$ the median concentrations ( $\geq 2 \mu \mathrm{g} / \mathrm{L}$ for mothers and $\geq 6 \mu \mathrm{g} / \mathrm{L}$ for fathers) compared to parents with estimated PBB exposure $<$ the median concentrations was attenuated $(\mathrm{AOR}=1.40,95 \% \mathrm{CI}: 0.84$, 2.35).
We examined the odds of a male birth by parents' enrollment PCB exposure in Table 4. In the model with only maternal PCB exposure (Model 1), there was no effect of maternal PCB exposure on the odds of a male birth. However, in the model with only paternal PCB exposure (Model 2), there was a non-significant increase in the odds of a male birth for offspring born to fathers with PCB $\geq 8 \mu \mathrm{g} / \mathrm{L}$ ( $\mathrm{n}=253$ offspring, $\mathrm{n}=144$ fathers, $\mathrm{AOR}=1.24$, 95\% CI: 0.81, 1.88; referent group: $\mathrm{PCB}<8 \mu \mathrm{g} / \mathrm{L}$ ). Increased odds of a male birth was also seen in the model with combined parents' PCB exposure (Model 3, n = 253 offspring, $\mathrm{n}=144$ pairs of mothers and fathers). The adjusted odds ratio was 1.53 (95\% CI: 0.93, 2.52) for offspring born to parents with PCB exposure $\geq$ the median concentrations $(\geq 6 \mu \mathrm{g} / \mathrm{L}$ for mothers and $\geq 8 \mu \mathrm{g} / \mathrm{L}$ for fathers) compared to parents with PCB exposure $<$ the median concentrations; however, the odds ratio was imprecise.

When we examined PBB and PCB exposure as continuous log-transformed variables, the results were consistent with those presented in Tables 2, 3 and 4. For the adjusted maternal PBB only model the AOR $=1.00$ (95\% CI: 0.80 , $1.25)$. For the paternal PBB only model, there was a $15 \%$ increase in the odds of a male birth for a $10 \mu \mathrm{g} / \mathrm{L}$ increase in the natural log of paternal PBB concentration (AOR = $1.15,95 \%$ CI: $0.80,1.65)$. In the combined maternal and paternal PBB model, there was a $6 \%$ increase in the odds of a male birth $(\mathrm{AOR}=1.06,95 \% \mathrm{CI}: 0.97,1.17)$ for a 10 $\mu \mathrm{g} / \mathrm{L}$ increase in the natural log of maternal and paternal PBB concentrations. For PCB exposure, the odds of a male birth for a $10 \mu \mathrm{g} / \mathrm{L}$ increase in the natural log of serum PCB concentrations were as follows: in the maternal PCB only model, a 25\% increase (AOR $=1.25,95 \% \mathrm{CI}: 0.79$, $1.98)$; in the paternal PCB only model, a $34 \%$ increase $(\mathrm{AOR}=1.34,95 \% \mathrm{CI}: 0.60,2.98) ;$ and in the combined maternal and paternal PCB model, a 13\% increase (AOR $=1.13,95 \%$ CI: $0.85,1.49)$.

We also examined enrollment PBB exposure categorized as three groups. In the model with maternal enrollment PBB only ( $\mathrm{n}=865$ offspring, $\mathrm{n}=479$ mothers), there was a non-significant increase in the odds of a male birth for offspring born to mothers with moderate $\mathrm{PBB}$ exposure $(\mathrm{PBB}>1-<4 \mu \mathrm{g} / \mathrm{L}, \mathrm{n}=268$ offspring, $\mathrm{AOR}=1.22,95 \%$ CI: $0.89,1.67)$ compared to mothers with low PBB exposure $(\mathrm{PBB} \leq 1 \mu \mathrm{g} / \mathrm{L}, \mathrm{n}=308$ offspring). This was less evident for mothers with high $\mathrm{PBB}$ exposure compared to mothers with low PBB exposure (PBB $\geq 4 \mu \mathrm{g} / \mathrm{L}, \mathrm{n}=289$ offspring, $\mathrm{AOR}=1.05,95 \% \mathrm{CI}: 0.77,1.43)$. In the model with paternal enrollment PBB only $(\mathrm{n}=300$ offspring, $\mathrm{n}=$ 171 fathers), we found increased odds of a male birth for offspring born to fathers with moderate $\mathrm{PBB}$ exposure $(\mathrm{PBB}>1-<6 \mu \mathrm{g} / \mathrm{L}, \mathrm{n}=135$ offspring, $\mathrm{AOR}=1.53,95 \%$ CI: $0.81,2.89)$ and high $\mathrm{PBB}$ exposure $(\mathrm{PBB} \geq 6 \mu \mathrm{g} / \mathrm{L}, \mathrm{n}=$ 
Table I: Characteristics of Michigan births and unadjusted odds ratios for a male birth from parents in the Michigan Long-Term PBB Study ( $n=865$ offspring born 1975-1988)

\begin{tabular}{|c|c|c|}
\hline Characteristic & $\begin{array}{c}\mathrm{N} \% \\
\text { Offspring }\end{array}$ & $\begin{array}{c}\text { Unadjusted } \\
\mathrm{OR}^{\wedge}(95 \% \mathrm{Cl})\end{array}$ \\
\hline \multicolumn{3}{|c|}{ Maternal age at offspring's birth (years) } \\
\hline$<30$ & $735(85)$ & 1.00 \\
\hline$\geq 30$ & $130(15)$ & $1.29(0.89,1.86)$ \\
\hline \multicolumn{3}{|c|}{ Paternal age at offspring's birth (years) } \\
\hline$<35$ & $740(89)$ & 1.00 \\
\hline$\geq 35$ & $89(11)$ & $0.95(0.64,1.39)$ \\
\hline \multicolumn{3}{|c|}{ Maternal education at offspring's birth } \\
\hline$\leq \mathrm{HS}$ & $543(63)$ & 1.00 \\
\hline$>\mathrm{HS}$ & $320(37)$ & $1.09(0.83,1.42)$ \\
\hline \multicolumn{3}{|c|}{ Paternal education at offspring's birth } \\
\hline$\leq \mathrm{HS}$ & $524(63)$ & 1.00 \\
\hline$>\mathrm{HS}$ & $304(37)$ & $1.06(0.81,1.38)$ \\
\hline \multicolumn{3}{|c|}{ Maternal BMI at enrollment $\left(\mathrm{kg} / \mathrm{m}^{2}\right)^{*}$} \\
\hline$<18.5$ & $60(9)$ & $0.93(0.55,1.58)$ \\
\hline $18.5-24.9$ & $466(67)$ & 1.00 \\
\hline$\geq 25$ & $|7|(24)$ & $0.96(0.72,1.29)$ \\
\hline \multicolumn{3}{|c|}{ Paternal BMI at enrollment $\left(\mathrm{kg} / \mathrm{m}^{2}\right)^{*}$} \\
\hline$<18.5$ & $4(1)$ & $0.77(0.27,2.23)$ \\
\hline $18.5-24.9$ & $173(57)$ & 1.00 \\
\hline$\geq 25$ & $129(42)$ & $\mathrm{I} .43(0.98,2.09)$ \\
\hline
\end{tabular}


Table I: Characteristics of Michigan births and unadjusted odds ratios for a male birth from parents in the Michigan Long-Term PBB Study ( $\mathrm{n}=865$ offspring born 1975-1988) (Continued)

\begin{tabular}{lll}
\hline Months unprotected intercourse to achieve pregnancy ** & & \\
\hline I-3 months & $300(59)$ & 1.00 \\
\hline$>3$ months & $210(4 I)$ & $0.94(0.67,1.31)$ \\
\hline
\end{tabular}

Birth order

\begin{tabular}{llll}
\hline First-born & $325(38)$ & 1.00 \\
\hline Non first-born & $540(62)$ & $1.08(0.81,1.42)$ \\
\hline
\end{tabular}

\begin{tabular}{lll}
\hline Offspring gestation (weeks) & & \\
\hline$<37$ & $30(4)$ & $1.78(0.86,3.67)$ \\
\hline 37 to $<42$ & $664(77)$ & 1.00 \\
\hline$\geq 42$ & $165(19)$ & $0.99(0.71,1.37)$ \\
\hline
\end{tabular}

$\wedge$ ORs are unadjusted for covariates, but adjusted for offspring born to the same mother or father

* Maternal enrollment BMI restricted to mothers' ages $\geq 16$ years and fathers' ages $\geq 19$ years

** Mothers who reported "doing something to prevent the pregnancy" were not asked the follow-up question of how many months of unprotected intercourse it took to achieve pregnancy (for $n=112$ offspring)

140 offspring, $\mathrm{AOR}=1.69,95 \% \mathrm{CI}: 0.85,3.34)$ when either were compared to fathers with low PBB exposure (PBB $\leq 1 \mu \mathrm{g} / \mathrm{L}, \mathrm{n}=25$ offspring). In the combined maternal and paternal enrollment PBB model ( $\mathrm{n}=300$ offspring, $\mathrm{n}=171$ mothers and fathers), we considered where both parents had high PBB exposure (maternal PBB $\geq 4 \mu \mathrm{g} / \mathrm{L}$ and paternal $\mathrm{PBB} \geq 6 \mu \mathrm{g} / \mathrm{L}, \mathrm{n}=81$ offspring) and compared this to the referent group where both parents had low $\mathrm{PBB}$ exposure (maternal PBB $<4 \mu \mathrm{g} / \mathrm{L}$ and paternal $\mathrm{PBB}<6 \mu \mathrm{g} / \mathrm{L}, \mathrm{n}=19$ offspring). We found increased odds of a male birth when both parents had high PBB exposure after adjusting for paternal BMI and year of offspring's birth (AOR $=2.56,95 \% \mathrm{CI}: 1.32,4.98)$. Finally, in the model with all other combinations of parents' PBB exposure (where parents' had discordant exposure levels, $\mathrm{n}=200$ offspring) compared to the referent group of parents with low PBB exposure ( $\mathrm{n}=19$ offspring) the odds ratio was in the same direction, but attenuated $(\mathrm{AOR}=$ $1.24,95 \%$ CI: 0.64, 2.38). The models with estimated PBB exposure categorized as three groups had similar results.

To verify our findings presented above, we performed two additional analyses. First, because the decay model was used to estimate PBB exposure backwards for offspring born before their parents exposure was collected, we repeated the adjusted models in Table 3 excluding those offspring ( $\mathrm{n}=116$ offspring born before their mothers' PBB measurement; $\mathrm{n}=118$ offspring born before their fathers' PBB measurement). For the maternal estimated PBB only model ( $\mathrm{n}=565$ offspring, 340 mothers), the results did not change from those in Table 3, Model 1 (maternal estimated PBB $\geq 2 \mu \mathrm{g} / \mathrm{L}$ : AOR $=0.99,95 \% \mathrm{CI}$ : 0.72-1.37; referent group: maternal estimated $\mathrm{PBB}<2 \mu \mathrm{g} /$ $\mathrm{L})$. For the paternal estimated PBB only model $(\mathrm{n}=179$ offspring, 118 fathers), the adjusted odds ratio was larger than in Table 3, Model 2 (paternal estimated PBB $\geq 6 \mu \mathrm{g} /$ $\mathrm{L}: \mathrm{AOR}=1.63,95 \% \mathrm{CI}$ : 0.94-2.83; referent group: paternal estimated $\mathrm{PBB}<6 \mu \mathrm{g} / \mathrm{L})$. Likewise, for the combined maternal and paternal estimated PBB model ( $\mathrm{n}=138$ offspring, $\mathrm{n}=98$ pairs of mothers and fathers), the adjusted odds ratio was increased but had wide confidence intervals due to small numbers (maternal estimated $\mathrm{PBB} \geq 2$ $\mu \mathrm{g} / \mathrm{L}$ and paternal estimated $\mathrm{PBB} \geq 6 \mu \mathrm{g} / \mathrm{L}, \mathrm{n}=43$ offspring: $\mathrm{AOR}=2.47,95 \% \mathrm{CI}: 1.15-5.28$; referent group: maternal estimated $\mathrm{PBB}<2 \mu \mathrm{g} / \mathrm{L}$ and paternal estimated $\mathrm{PBB}<6 \mu \mathrm{g} / \mathrm{L}, \mathrm{n}=56$ offspring).

Second, because changes in BMI or pregnancy and breastfeeding history may affect mothers' PBB or PCB concentrations, we restricted the enrollment maternal models to include only the first offspring born after the mothers' enrollment PBB or PCB concentration was measured. For 
Table 2: Odds ratios (OR) for a male birth among offspring from parents in the Michigan Long-Term PBB Study with enrollment serum PBB concentrations

\begin{tabular}{|c|c|c|c|c|}
\hline & $\mathrm{N}(\%)$ & Crude $^{\wedge}$ & Unadjusted * & Adjusted ** \\
\hline Exposure Variables ( $\mu \mathrm{g} / \mathrm{L})$ & Offspring & OR $(95 \% \mathrm{Cl})$ & OR $(95 \% \mathrm{Cl})$ & OR $(95 \% \mathrm{Cl})$ \\
\hline \multicolumn{5}{|c|}{ Model I (Maternal enrollment PBB only): } \\
\hline Maternal PBB & 865 & & & \\
\hline$<3$ & $477(55)$ & 1.00 & 1.00 & 1.00 \\
\hline$\geq 3$ & $388(45)$ & $0.92(0.70,1.21)$ & $0.93(0.72,1.20)$ & $0.93(0.72,1.20)$ \\
\hline
\end{tabular}

Model 2 (Paternal enrollment PBB only):

\begin{tabular}{lcccc}
\hline Paternal PBB & 300 & & & \\
\hline$<6$ & $160(53)$ & 1.00 & 1.00 & 1.00 \\
\hline$\geq 6$ & $140(47)$ & $1.11(0.70,1.75)$ & $0.95(0.65,1.39)$ & $1.18(0.76,1.83)$ \\
\hline
\end{tabular}

Model 3 (Maternal and Paternal enrollment PBB combined):

\begin{tabular}{cccccc}
\hline Maternal PBB & Paternal PBB & 300 & & & \\
\hline$<3$ & $<6$ & $120(40)$ & 1.00 & 1.00 & 1.00 \\
\hline other combinations & & $70(23)$ & $0.99(0.55,1.79)$ & $0.84(0.52,1.37)$ & $0.92(0.61,1.40)$ \\
\hline$\geq 3$ & $\geq 6$ & $110(37)$ & $1.35(0.80,2.28)$ & $1.14(0.73,1.79)$ & $1.43(0.89,2.29)$ \\
\hline
\end{tabular}

$\wedge$ Crude ORs are unadjusted for covariates or offspring born to the same mother or father

* ORs are unadjusted for covariates, but adjusted for offspring born to the same mother or father

** AORs are adjusted for covariates (Model I adjusted for year of offspring's birth; Models 2 and 3 adjusted for year of offspring's birth and paternal $\mathrm{BMI}$ as low and normal vs. high) and adjusted for offspring born to the same mother or father

the maternal enrollment PBB only model ( $\mathrm{n}=407$ offspring), the adjusted odds ratio was comparable to Table 2, Model 1 (maternal PBB $\geq 3 \mu \mathrm{g} / \mathrm{L}:$ AOR $=0.91,95 \% \mathrm{CI}$ : $0.61-1.35$; referent group: maternal $\mathrm{PBB}<3 \mu \mathrm{g} / \mathrm{L})$. For the maternal enrollment PCB only model ( $\mathrm{n}=346$ offspring), the odds ratio was 1.39 (95\% CI: 0.89-2.17), for offspring born to mothers with $\mathrm{PCB} \geq 6 \mu \mathrm{g} / \mathrm{L}$ compared to mothers with $\mathrm{PCB}<6 \mu \mathrm{g} / \mathrm{L}$.

\section{Discussion}

Among this Michigan cohort of 865 offspring with potential in utero PBB exposure, the overall proportion of male births was 0.542 . This was higher than the national male proportion of 0.514 [21] and higher than that of Michigan births over the same time period (range: 0.511-0.516, Source: 1975-1988 Live Birth Files, Vital Records and Health Data Development Section, MDCH). When we considered the subset of births where both parents were in the cohort, there was a suggestion of increased odds of a male birth among offspring born to where both parents had PBB exposure $\geq$ the median concentrations. The results were consistent when both parents had PCB exposure $\geq$ the median concentrations. When PBB exposure was categorized into three groups, we found a statistically significant increase in the odds of a male birth where both parents had high PBB exposure compared to where both parents had low PBB exposure, but the referent group was based on small numbers and the confidence interval became wide. In models where only one parent's exposure was considered, there was a suggestion of increased odds of a male birth for paternal PBB or PCB exposure only, but not for maternal PBB or PCB exposure only.

To our knowledge, this is the first study to investigate the relationship of the secondary sex ratio and PBB exposure. Therefore, comparison of our results is limited to studies that have measured other polyhalogenated aromatic hydrocarbons, such as PCBs, dioxins, and furans. A few studies that considered PCB exposure found increases in the sex ratio $[31,35,36]$, which is similar to our findings. 
Table 3: Odds ratios (OR) for a male birth among offspring from parents in the Michigan Long-Term PBB Study with estimated serum PBB concentrations

\begin{tabular}{lllll}
\hline & $\mathrm{N}(\%)$ & Crude $^{\wedge}$ & Unadjusted * & Adjusted** \\
\hline Exposure Variables $(\mu \mathrm{g} / \mathrm{L})$ & Offspring & OR $(95 \% \mathrm{Cl})$ & OR $(95 \% \mathrm{Cl})$ & OR $(95 \% \mathrm{Cl})$ \\
\hline
\end{tabular}

Model I (Maternal estimated PBB only):

\begin{tabular}{|c|c|c|c|c|}
\hline Maternal PBB & 681 & & & \\
\hline$<2$ & $354(52)$ & 1.00 & 1.00 & 1.00 \\
\hline$\geq 2$ & $327(48)$ & $0.97(0.72,1.32)$ & $0.97(0.73,1.29)$ & $1.00(0.75,1.33)$ \\
\hline \multicolumn{5}{|c|}{ Model 2 (Paternal estimated PBB only): } \\
\hline Paternal PBB & 297 & & & \\
\hline$<6$ & $167(56)$ & 1.00 & 1.00 & 1.00 \\
\hline$\geq 6$ & $130(44)$ & $1.05(0.67,1.67)$ & $0.90(0.6 \mathrm{I}, \mathrm{I} .32)$ & $\mathrm{I} .08(0.7 \mathrm{I}, \mathrm{I} .66)$ \\
\hline
\end{tabular}

Model 3 (Maternal and Paternal estimated PBB combined):

\begin{tabular}{cccccc}
\hline Maternal PBB & Paternal PBB & 226 & & & \\
\hline$<2$ & $<6$ & $83(37)$ & 1.00 & 1.00 & 1.00 \\
\hline other combinations & & $65(29)$ & $0.87(0.45,1.67)$ & $0.89(0.50,1.59)$ & $0.87(0.52,1.46)$ \\
\hline 22 & $\geq 6$ & $78(34)$ & $1.21(0.65,2.27)$ & $1.13(0.67,1.90)$ & $1.40(0.84,2.35)$ \\
\hline
\end{tabular}

$\wedge$ Crude ORs are unadjusted for covariates or offspring born to the same mother or father

* ORs are unadjusted for covariates, but adjusted for offspring born to the same mother or father

** AORs are adjusted for covariates (Model I adjusted for year of offspring's birth; Models 2 and 3 adjusted for year of offspring's birth and paternal

$\mathrm{BMI}$ as low and normal vs. high) and adjusted for offspring born to the same mother or father

Further, several studies have found associations with fathers exposure but not necessarily mothers exposure in relation to the sex ratio (reviewed in [24]). Our results were not consistent, however, with other studies that found a decrease in the secondary sex ratio with parental exposure to related chemicals [26-32].

The biological mechanism by which exposure to PBBs may influence sex ratio remains unclear. The main congener in the mixture of PBBs to which the Michigan residents were exposed was PBB-153, which has been shown to exhibit estrogenic, anti-estrogenic, or anti-androgenic activity, similarly as for some PCB congeners $[42,43]$. Additionally, there is some evidence to suggest that possible alterations in sex ratio may be influenced by parental hormone levels around the time of conception [44]. However, it is unknown if PBBs mediate changes in parental hormone levels that would increase the odds of a male birth, as seen in our study. On the paternal side, whether exposure to these types of chemicals causes the preferen- tial survival of $\mathrm{Y}$ sperm over $\mathrm{X}$ sperm has been considered as a possible mechanism; although the findings in studies have been inconsistent $[45,46]$. On the maternal side, it is unknown whether exposure to these types of chemical could cause an increase in early loss of XX embryos.

Our sample included 865 offspring born to mothers in the cohort during 1975-1988, but only 300 offspring born to fathers in the cohort. This may have biased our results because mothers and fathers who were both in the cohort had higher serum PBB concentrations compared to where only the mother was in the cohort but not the father. In addition, we excluded birth records for offspring born to cohort mothers after 1988. When we considered a model with only maternal enrollment PBB for all available data $(\mathrm{n}=1392$ offspring; $\mathrm{n}=865$ born 1975-1988; $\mathrm{n}$ = 527 born 1989-2005), there remained no effect of maternal exposure on the odds of a male birth (maternal $\mathrm{PBB} \geq 3 \mu \mathrm{g} / \mathrm{L}: \mathrm{AOR}=1.04,95 \%$ CI: 0.85-1.28; referent group: maternal $\mathrm{PBB}<3 \mu \mathrm{g} / \mathrm{L}$ ). Ultimately, we excluded 
Table 4: Odds ratios (OR) for a male birth among offspring from parents in the Michigan Long-Term PBB Study with enrollment serum PCB concentrations

\begin{tabular}{|c|c|c|c|c|}
\hline & $\mathrm{N}(\%)$ & Crude $^{\wedge}$ & Unadjusted $*$ & Adjusted** \\
\hline Exposure Variables ( $\mu \mathrm{g} / \mathrm{L})$ & Offspring & OR $(95 \% \mathrm{Cl})$ & OR $(95 \% \mathrm{Cl})$ & OR $(95 \% \mathrm{Cl})$ \\
\hline \multicolumn{5}{|c|}{ Model I (Maternal PCB only): } \\
\hline Maternal PCB & 790 & & & \\
\hline$<6$ & $444(56)$ & 1.00 & 1.00 & 1.00 \\
\hline$\geq 6$ & $346(44)$ & $1.02(0.77,1.35)$ & $0.99(0.76,1.30)$ & $1.01(0.77,1.32)$ \\
\hline
\end{tabular}

Model 2 (Paternal PCB only):

\begin{tabular}{lllll}
\hline Paternal PCB & 253 & & & \\
\hline$<8$ & $141(56)$ & 1.00 & 1.00 & 1.00 \\
\hline$\geq 8$ & $112(44)$ & $1.06(0.64,1.75)$ & $1.23(0.83,1.82)$ & $1.24(0.81,1.88)$ \\
\hline
\end{tabular}

Model 3 (Maternal and Paternal PCB combined):

\begin{tabular}{cccccc}
\hline Maternal PCB & Paternal PCB & 253 & & & \\
\hline$<6$ & $<8$ & $80(32)$ & 1.00 & 1.00 & 1.00 \\
\hline other combinations & & $116(46)$ & $1.26(0.71,2.22)$ & $1.23(0.77,1.97)$ & $1.00(0.63,1.57)$ \\
\hline 26 & $\geq 8$ & $57(22)$ & $1.13(0.57,2.24)$ & $1.39(0.81,2.40)$ & $1.53(0.93,2.52)$ \\
\hline
\end{tabular}

$\wedge$ Crude ORs are unadjusted for covariates or offspring born to the same mother or father

* ORs are unadjusted for covariates, but adjusted for offspring born to the same mother or father

** AORs are adjusted for covariates (Model I adjusted for year of offspring's birth; Models 2 and 3 adjusted for year of offspring's birth and paternal

$\mathrm{BMI}$ as low and normal vs. high) and adjusted for offspring born to the same mother or father

these later offspring from our study sample because we could not effectively account for any secular trends in sex ratio, which may have affected the later births. In addition, the estimated maternal PBB at conception would have been based on maternal enrollment PBB collected more than 13 years before these offspring were born. We obtained the sex of offspring from electronic birth records, but we could not obtain records for out of state births. It is unlikely that this was a source of bias, because the proportion male birth among the 84 out of state births (proportion male $=0.548$ ) was not different to that of our final sample (proportion male $=0.542$ ). Among the 33 offspring where the mother did not have a PBB measurement, the proportion male birth was slightly less (proportion male $=0.485$ ). Based on the results of our study, paternal $\mathrm{PBB}$ exposure had a greater effect than maternal PBB exposure on the odds of a male birth. However, determining whether either parent's exposure separately or their combined exposure would contribute to a skewed sex ratio was complicated because exposure levels from parents in the same family were correlated.
We considered several covariates and their association with the odds of a male birth. We found increased odds of a male birth for high paternal BMI (BMI $\left.\geq 25 \mathrm{~kg} / \mathrm{m}^{2}\right)$, but not for high maternal BMI. In this population, BMI has been shown to slow the decay of PBB in the body $[15,40]$. Therefore, as a confounder, we retained paternal BMI in models where paternal exposure was considered. Although, we cannot rule out the potential for bias, given that weight and height were self-reported by participants. It is possible that the heavier fathers at enrollment into the cohort had higher concentrations of PBB at the time of their offspring's conception. Maternal weight or BMI has been considered in other sex ratio studies $[31,47]$, but to our knowledge this is the first study to consider paternal BMI in relation to the odds of a male birth. As expected, for gestational age we found increased odds of a male birth for offspring born prior to 37 weeks gestation. However, we have previously found no association between gestational age and PBB exposure in this population $[8,9]$, and thus gestational age was not a confounder in our analyses. We did not find an association with other factors that 
are reported to influence the secondary sex ratio, such as maternal and paternal age or birth order.

\section{Conclusion}

Our results add to the body of literature on the possible effects of environmental pollutants on the secondary sex ratio. This study includes a well-defined period of PBB exposure, and over 30 years of birth record and cohort registry data from the Long-Term study. In this population, paternal exposure alone and combined maternal and paternal exposure (for PBB or PCB) increased the odds of a male birth. Further research is needed to corroborate these findings and shed light on the biological mechanisms by which these types of chemicals may influence the secondary sex ratio.

\section{Abbreviations}

PBB: polybrominated biphenyl; PCB: polychlorinated biphenyl; BMI: body mass index; $\mu \mathrm{g} / \mathrm{L}$ : microgram per liter; LOD: limit of detection; OR: odds ratio; CI: confidence interval; AOR: adjusted odds ratio.

\section{Competing interests}

The authors declare that they have no competing interests.

\section{Authors' contributions}

All authors have made substantial contribution to this study and to the writing and editing of this manuscript. Additional contributions are as follows: MM, LC and CS designed the study and provided historical cohort data; JW retrieved and matched cohort records and verified offspring/parental relationships; $\mathrm{MT}$ and $\mathrm{AB}$ performed statistical analyses. All authors read and approved the final manuscript.

\section{Acknowledgements}

Research was funded by the NIEHS (grants ROI-ES0834I and ROIESO I 20 I4), the US EPA (grant R825300) and supported by the Centers for Disease Control and Prevention cooperative agreement U37/CCU500392. We thank the staff of the Michigan Department of Community Health, participants of the Michigan Long-Term PBB Study, and Gabriel Rainisch for his early work on these analyses. Thanks also to Glenn Copeland, State Registrar and Director, Michigan Division for Vital Records and Health Statistics, for providing the linked electronic birth record data used in this study.

\section{References}

I. Landrigan PJ, Wilcox KR Jr, Silva J Jr, Humphrey HE, Kauffman C, Heath CW Jr: Cohort study of Michigan residents exposed to polybrominated biphenyls: epidemiologic and immunologic findings. Ann N Y Acad Sci 1979, 320:284-294.

2. Fries GF: The PBB episode in Michigan: an overall appraisal. Crit Rev Toxicol 1985, I 6:105-156.

3. Humphrey H, Hayner N: Polybrominated Biphenyls: An agricultural incident and its consequences: An epidemiological investigation of human exposure. Trace Subst Environ Health 1976, 9:57-63.

4. Kay K: Polybrominated biphenyls (PBB) environmental contamination in Michigan, 1973-1976. Environ Res 1977, 13:74-93.

5. Blanck HM, Marcus M, Tolbert PE, Rubin C, Henderson AK, Hertzberg VS, Zhang RH, Cameron L: Age at menarche and tanner stage in girls exposed in utero and postnatally to polybrominated biphenyl. Epidemiology 2000, I I:64 I-647.

6. Davis SI, Blanck HM, Hertzberg VS, Tolbert PE, Rubin C, Cameron LL, Henderson AK, Marcus M: Menstrual function among women exposed to polybrominated biphenyls: a follow-up prevalence study. Environ Health 2005, 4:15.

7. Small CM, Cheslack-Postava K, Terrell M, Blanck HM, Tolbert P, Rubin C, Henderson A, Marcus M: Risk of spontaneous abortion among women exposed to polybrominated biphenyls. Environ Res 2007, 1 05:247-255.

8. Sweeney AM, Symanski E: The influence of age at exposure to PBBs on birth outcomes [see comment]. Environ Res 2007, 1 05:370-379.

9. Givens ML, Small CM, Terrell ML, Cameron LL, Michels Blanck H, Tolbert PE, Rubin C, Henderson AK, Marcus M: Maternal exposure to polybrominated and polychlorinated biphenyls: Infant birth weight and gestational age. Chemosphere 2007, 69: $1295-1304$.

10. Hoffman CS, Small CM, Blanck HM, Tolbert P, Rubin C, Marcus M: Endometriosis among women exposed to polybrominated biphenyls. Ann Epidemiol 2007, I 7:503-510.

II. Agency for Toxic Substances and Disease Registry (ATSDR): Toxicological profile for polychlorinated biphenyls (PCBs). Atlanta, GA: U.S. Department of Health and Human Services, Public Health Service; 2000.

12. Kreiss K, Roberts C, Humphrey HE: Serial PBB levels, PCB levels, and clinical chemistries in Michigan's PBB cohort. Arch Environ Health 1982, 37:141-147.

13. Kreiss K: Studies on populations exposed to polychlorinated biphenyls. Environ Health Perspect 1985, 60:193-199.

14. Rosen DH, Flanders WD, Friede A, Humphrey HE, Sinks TH: Halflife of polybrominated biphenyl in human sera. Environ Health Perspect 1995, 103:272-274.

15. Blanck HM, Marcus M, Hertzberg V, Tolbert PE, Rubin C, Henderson $\mathrm{AK}$, Zhang $\mathrm{RH}$ : Determinants of polybrominated biphenyl serum decay among women in the Michigan PBB cohort. Environ Health Perspect 2000, I08: 147-152.

16. Shirai JH, Kissel JC: Uncertainty in estimated half-lives of PCBS in humans: impact on exposure assessment. Sci Total Environ 1996, 187:199-210.

17. Eyster JT, Humphrey HE, Kimbrough RD: Partitioning of polybrominated biphenyls (PBBs) in serum, adipose tissue, breast milk, placenta, cord blood, biliary fluid, and feces. Arch Environ Health 1983, 38:47-53.

18. Miceli JN, Nolan DC, Marks B, Hariharan M: Persistence of polybrominated biphenyls (PBB) in human post-mortem tissue. Environ Health Perspect 1985, 60:399-403.

19. Jacobson JL, Fein GG, Jacobson SW, Schwartz PM, Dowler JK: The transfer of polychlorinated biphenyls (PCBs) and polybrominated biphenyls (PBBs) across the human placenta and into maternal milk. Am J Public Health 1984, 74:378-379.

20. Marcus M, Kiely J, Xu F, McGeehin M, Jackson R, Sinks T: Changing sex ratio in the United States, 1969-1995. Fertil Steril 1998, 70:270-273.

21. Mathews TJ, Hamilton BE: Trend analysis of the sex ratio at birth in the United States. Natl Vital Stat Rep. 2005, 53(20): I-I 7.

22. Moller $\mathrm{H}$ : Change in male:female ratio among newborn infants in Denmark [see comment][comment]. Lancet 1996, 348:828-829.

23. Allan BB, Brant R, Seidel JE, Jarrell JF: Declining sex ratios in Canada [see comment] [erratum appears in Can Med Assoc J I997 Feb I; I 56(3):348]. CMAJ. I997, I 56(I):37-4I.

24. James $\mathrm{WH}$ : Offspring sex ratios at birth as markers of paternal endocrine disruption. Environ Res 2006, I 00:77-85.

25. Cordier S: Evidence for a role of paternal exposures in developmental toxicity. Basic Clin Pharmacol Toxicol 2008, 102:176-I8I.

26. Mocarelli P, Gerthoux PM, Ferrari E, Patterson DG Jr, Kieszak SM, Brambilla P, Vincoli N, Signorini S, Tramacere P, Carreri V, Sampson EJ, Turner WE, Needham LL: Paternal concentrations of dioxin and sex ratio of offspring. Lancet 2000, 355:।858-I863.

27. Hertz-Picciotto I, Jusko TA, Willman EJ, Baker RJ, Keller JA, Teplin SW, Charles MJ: A cohort study of in utero polychlorinated biphenyl (PCB) exposures in relation to secondary sex ratio. Environ Health 2008, 7:37.

28. Weisskopf M, Anderson HA, Hanrahan LP, Great Lakes Consortium: Decreased sex ratio following maternal exposure to poly- 
chlorinated biphenyls from contaminated Great Lakes sport-caught fish: a retrospective cohort study. Environ Health. 2003, 2(I):2.

29. Ryan JJ, Amirova Z, Carrier G: Sex ratios of children of Russian pesticide producers exposed to dioxin. Environ Health Perspect 2002, I 1 0:A699-701.

30. Mackenzie CA, Lockridge $A$, Keith $M$ : Declining sex ratio in a first nation community. Environ Health Perspect 2005, I I 3: I 295- 1298.

31. Taylor KC, Jackson LW, Lynch CD, Kostyniak PJ, Buck Louis GM Preconception maternal polychlorinated biphenyl concentrations and the secondary sex ratio. Environ Res 2007 , 103:99-105.

32. del Rio Gomez I, Marshall T, Tsai P, Shao YS, Guo YL: Number of boys born to men exposed to polychlorinated byphenyls. Lancet 2002, 360:143-144.

33. Schnorr TM, Lawson CC, Whelan EA, Dankovic DA, Deddens JA, Piacitelli LA, Reefhuis J, Sweeney MH, Connally LB, Fingerhut MA: Spontaneous abortion, sex ratio, and paternal occupational exposure to 2,3,7,8-tetrachlorodibenzo-p-dioxin. Environ Health Perspect 200I, 109:I I27-II32.

34. Michalek JE, Rahe AJ, Boyle CA: Paternal dioxin and the sex of children fathered by veterans of Operation Ranch Hand. Epidemiology 1998, 9:474-475.

35. Yoshimura T, Kaneko S, Hayabuchi $\mathrm{H}$ : Sex ratio in offspring of those affected by dioxin and dioxin-like compounds: the Yusho, Seveso, and Yucheng incidents. Occup Environ Med 200I, 58:540-54I.

36. Karmaus W, Huang S, Cameron L: Parental concentration of dichlorodiphenyl dichloroethene and polychlorinated biphenyls in Michigan fish eaters and sex ratio in offspring. J Occup Environ Med 2002, 44:8-13.

37. Agency for Toxic Substances and Disease Registry (ATSDR): Toxicological profile for polybrominated biphenyls and polybrominated diphenyl ethers. Atlanta GA: U.S. Department of Health and Human Services, Public Health Service; 2004.

38. Burse VW, Needham LL, Liddle JA, Bayse DD, Price HA: Interlaboratory comparison for results of analyses for polybrominated biphenyls in human serum. J Anal Toxicol 1980, 4:22-26.

39. Needham LL, Burse VW, Price HA: Temperature-programmed gas chromatographic determination of polychlorinated and polybrominated biphenyls in serum. J Assoc Off Anal Chem 198I, 64: $1131-1137$

40. Terrell ML, Manatunga AK, Small CM, Cameron LL, Wirth J, Blanck HM, Lyles RH, Marcus M: A Decay Model for Assessing Polybrominated Biphenyl Exposure Among Women in the Michigan Long-Term PBB Study. J Expo Sci Environ Epidemiol. 2008, 18(4):410-420.

4I. SAS Institute I: SAS/STAT Software: Changes and Enhancements for Release 6.12. Cary, NC.: SAS Institute, Inc; 1996.

42. Bonefeld-Jorgensen EC, Andersen HR, Rasmussen TH, Vinggaard AM: Effect of highly bioaccumulated polychlorinated biphenyl congeners on estrogen and androgen receptor activity. Toxicology 2001, 158: |4|-153.

43. Nakari T, Pessala P: In vitro estrogenicity of polybrominated flame retardants. Aquat Toxicol 2005, 74:272-279.

44. James WH: Evidence that mammalian sex ratios at birth are partially controlled by parental hormone levels at the time of conception. J Theor Biol 1996, 180:27|-286.

45. Tiido T, Rignell-Hydbom A, Jonsson BA, Giwercman YL, Pedersen HS, Wojtyniak B, Ludwicki JK, Lesovoy V, Zvyezday V, Spano M, Manicardi GC, Bizzaro D, Bonefeld-Jorgensen EC, Toft G, Bonde JP. Rylander L, Hagmar L, Giwercman A, Inuendo : Impact of PCB and P,P'-DDE contaminants on human sperm $Y: X$ chromosome ratio: studies in three European populations and the Inuit population in Greenland. Environ Health Perspect 2006, I I 4:718-724.

46. Tiido T, Rignell-Hydbom A, Jonsson B, Giwercman YL, Rylander L, Hagmar L, Giwercman A: Exposure to persistent organochlorine polluntants associates with human sperm $\mathbf{Y}: \mathbf{X}$ chromosome ratio. Hum Reprod 2005, 20(7): 1903-9.

47. Cagnacci A, Renzi A, Arangino S, Alessandrini C, Volpe A: Influences of maternal weight on the secondary sex ratio of human offspring. Hum Reprod 2004, 19:442-444.

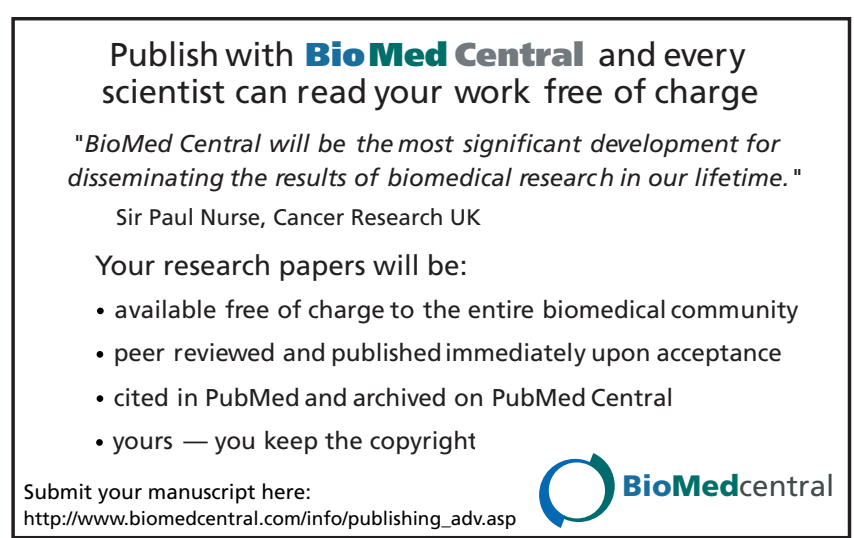

